\title{
A Surface Collection From the Klein Site at Melfort
}

\author{
By ROBERT W. NERO \\ Saskatchewan Museum of Natural History
}

he scientific excavation of archlogical sites, as exemplified by the rtlach Site report (Wettlaufer, 5, The Mortlach Site, Dept. of Resources, Regina. 113 pp. *), provide us with a wealth of innation about past peoples of Saskhewan. The introduction of the ntific method in excavations in area, with its emphasis on painsing methods of study, need not, vever, deter individuals with little ining or time from contributing the unfolding of the remarkable ma of human history which we witnessing. One of the most fruitarchaeological tasks for which persons qualify is the collection of terial fcund on the surface of the und. That this material has a real significant value is indicated by statement by Will and Hecker 44. Upper Missouri River Valley original Culture in North Dakota, D. Hist. Quart., 11:117) that their ective was to ". . . locate and list many village sites in this area, ore their surfaces have become ther obliterated by cultivation or sion and to preserve samples of sherds and other artifacts from th individual site." Surface matal, especially pottery and bone, is istantly undergoing deterioration cugh exposure and through manilation by machinery. The need for recovery of this material is far re pressing than for the excava$n$ af that which lies deeply interin the earth.

Surface finds occur as the result exposure of the subsoil through nd and water erosion, farming actices and other human activities rolving movement of soil, e.g. ad-building or grading, sand and avel excavation, etc. The one thing ich most surface archaeological terials have in common is a lack relative pesition within the soil, whatever stratigraphy existed, been lost. Cunsequently, in most tances surface collections repreht a mixture of cultures. Somenes it is possible to determine on basis of similarities of shape and slight shculder; A7 broad side-notchsubstance that surface finds represent a single culture. Nevertheless, even where this is not so, surface material supplies valuable data on the geographic distribution of particular cultures. Wettlaufer stated: "Not only dces this material reveal the location of archaeological sites but it is an important and necessary factor in plotting the distribution of any group of people over the province in prehistoric times." (1951. An archaeological survey of Saskatchewan No. 1, unpublished).

A surface collection recently donated to the Saskatchewan Museum of Natural History by Dennis and Larry Klein of Melfort, Saskatchewan may be used as a demonstration. The collection received by the museum consists of: 4 fully grooved hammers or mauls; 5 notched slab "hoes"; 35 projectile points; 8 projectile point fragments; 6 scrapers; 8 flake knives; 17 ovate blades; 1 musket ball; 1 brass projectile point; 1 large iron knife (Hudson Bay trade); 90 flint flakes.

All of this material was reported to have been found on the surface of a field on the edge of Stony Creek near Melfort, Sask. E1/2 24, 46, 19, W2nd), by Mr. Erwin L. Klein and sons, Dennis and Larry. A series cf projectile points, etc., from this collection may be seen in the photo. They have been arranged in a sequence based on their form, with some older types in the upper row and some more recent material in the lower row. The sequence of material in between dses not indicate anv knuwn cultural relationship. Note the variety of point shapes. Generally speaking, these points may be classified as follows (using purely descriptive terminology): A1, 2 lanceolate; A3 indented base, stemless; A4, 5, 6 parallel-sided stemmed,

* Copies of The Mortlach Site may be obtained on request from the Saskatchewan Museum of Natural History. 
ed; B1 to 7 side-notched, some with concave base; $\mathrm{C} 1$ to 8 corner-notched or stemmed; D1 to 3 variant sideand corner-notched; D4, 5 notched triangular; D6 brass point; D7 lead musket ball.

This variety of projectile points clearly indicates that a number of different peoples occupied the site. presumably over a long period of time. Scme of the points illustrated are so distinctive as to be diagnostic of particular "cultures." For example, A1 and 2 resemble types of points which have been found at a number of "Archaic" sites in the eastern United States; A4 matches "Yuma" or specifically "Scottsbluff Points," again, an "early man" type of artifact. Points $\mathrm{C} 1$ to 8 look very much like the "Pelican Lake" points shown by Wettlaufer (1955. The Mortlach Site, p. 107) and D4 and 5 have much in crinmon with his "Prairie Side-notchea" (p. 22).

The brass point, D6, represents the historic period, as does the lead musket ball. It would seem, then, on the basis of this collection of artifacts, that this site has been occupied by man from the very early period to late historic times. The discovery of this variety of points at a site on the very edge of the forested area of the province is exciting news and extends our knowledge of the distribution of prehistoric Plains cultures. This material points further to a need for archaeological surveys in the north as well as in the south.

A further utilization of surface material is obtained by inspection of the stcr 2 material involved. At cxcavated Mortlach Site, 272 ou 1606 flakes (or 16 per cent) f all levels were brown flint ( $\mathrm{K}$ River type) or "chalcedony." At Klein site the stone used is ma a kind of chert, chalcedony being presented cnly by one scraper, ovate blade ar. $d$ two flakes, a $n$ three per cent of the chipped $s$ artifacts and flakes which were lected. This ditference in the us a particular material is prob based on availability, the prin source of this flint being in $N$ Dakota. A simple distribution of the percentages of this kin flint in collections throughout province would be of particular terest. Thus, some evidence of use and distribution of stone mi ials might be gained. Distribu studies of material of specific limited origin as well as of type facts would be extremely useful cculd be done on the basis of face materials alone.

There is undoubtedly a consi $r$ able amount of information $w$ ? might be obtained on the basi collections already made by il $r$ ested individuals throughout province. To the extent that material is made available for $s$ cur knowledge of the distributic prehistoric peoples in this pror will be greatly advanced. With a ficient number of collections suc the one described above, it $u$ ld be possible even now to draw $r$ n conclusions regarding the histor of past cultures.

\section{Complementary Roles of the Profession 1 and Amateur Archaeologist}

An abstract by R. W. Nero of William A. Ritchie's article "Each to the Other" publisl in American Antiquity, $22: 169-170,1956, \cdot$ as No. 1 in a series of articles on the role of th rofessional and amateur archaeologist.

". . the growth of interest in prehistoric man within the population as a whole.. seems to reflect an intellectual curiosity which may temper in some measure the predominantly technological and commercial bent of our civilization. A large supporting public interest, furthermore, serves to sustain the professional archaeologist in his investigations

"But there is an inherent grave danger here, too, for this sur of interest and activity on the pa of ever increasing numbers of $p t$ le, imposes a threat of early destru ion of the limited, precious, and ten unique sources of our data of rehistory.

"It must" be obvious to all tha means of mutually supporting behavior between amateur and rofessional workers must be founc explored together and agreed upc In 